\title{
Volume-outcome relationships: Does practice really make perfect?
}

\author{
John Agzarian, MD, MPH, FRCSC, and Yaron Shargall, MD, FRCSC
}

\footnotetext{
From the Division of Thoracic Surgery, Department of Surgery, Faculty of Health Sciences, St. Joseph's Healthcare Hamilton, McMaster University, Hamilton, Ontario, Canada Disclosures: Authors have nothing to disclose with regard to commercial support.

Received for publication Jan 25, 2018; accepted for publication Jan 31, 2018; available ahead of print Feb 28, 2018.

Address for reprints: Yaron Shargall, MD, FRCSC, St Joseph's Healthcare Hamilton Room, T2105, 50 Charlton Ave E, Hamilton, Ontario L8N 4A6, Canada (E-mail: shargal@mcmaster.ca).

J Thorac Cardiovasc Surg 2018;155:2695-6

$0022-5223 / \$ 36.00$

Copyright (c) 2018 by The American Association for Thoracic Surgery

https://doi.org/10.1016/j.jtcvs.2018.01.074
}

Thoracic surgeons continue to cope with the ever-constant challenge of mitigating risk and decreasing complications. Luft and colleagues ${ }^{1}$ first reported a $41 \%$ lower caseadjusted postoperative death rate in high-volume institutions. Forty years later, the volume-outcome relationship has gained significant momentum. Several publications have supported the notion of a need for minimal volume standards and have been the impetus behind centralization of care. ${ }^{2-4}$ The concept is intuitive: centers that perform more surgeries should accordingly have the benefit of lower complications. More recent evaluation, however, has questioned this otherwise obvious premise.

In this issue of the Journal, in a study that used an administered database and predetermined hospital volume cutoffs, Harrison and colleagues ${ }^{5}$ compared short-term outcome differences after lobectomies and pneumonectomies and after esophagectomies. A propensity score-matched analysis demonstrated no major differences between low- and highvolume centers with regard to in-hospital mortality and major complications. Essentially, Harrison and colleagues ${ }^{5}$ argue that surgical volume in isolation does not capture the magnitude of differences among centers, and it is perhaps these inherent differences between institutions (such as patient comorbidities, socioeconomic status, and age) that actually account for observed surgical outcome differences.

This work by Harrison and colleagues ${ }^{5}$ certainly challenges the status quo, and it is in line with more recent literature that questions the almost dogmatic approach that links lower complication and mortality with higher volumes. In their recent review, Kozower and Stukenborg ${ }^{6}$ highlight key issues challenging volume-outcome research and its associated conclusions. First, volume cutoffs are arbitrarily assigned and analyzed categorically, as opposed to as continuous variables (which would be better for evaluating whether a linear relationship exists). Second, most studies do not account for clustering effects within hospitals (the assumption that individuals within a single institution

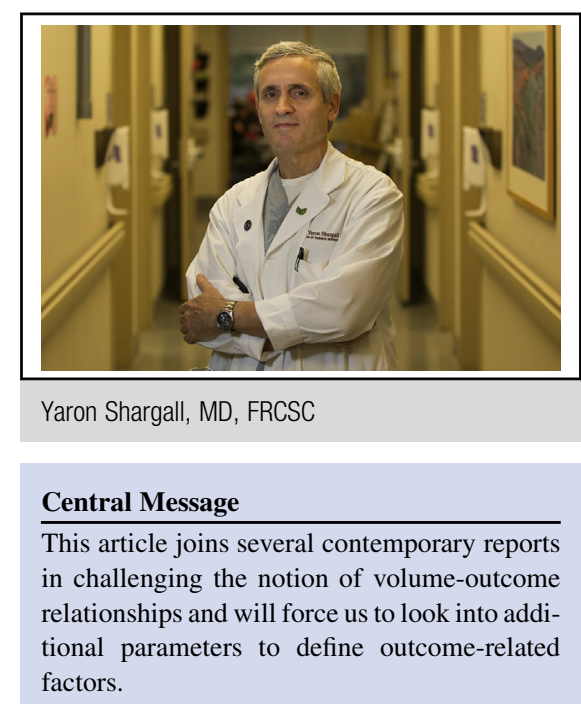

See Article page 2683.

may be correlated) and therefore underestimate variance while inflating effect size. Finally, most research in this field relies on administrative data sets that generally lack granular patient-specific details and provide large sample size with increased potential for statistical significance but not clinically meaningful differences. Fittingly, a recent report from Ontario, Canada, where regionalization of thoracic surgery was implemented in 2007, demonstrated that centralization to high-volume centers was not associated with improved operative mortality.

By using a propensity-matched analysis, the current study by Harrison and colleagues ${ }^{5}$ attempts to control for baseline differences between high- and low-volume centers, other than of surgical volumes themselves, that can account for differences in outcomes. The results support the notion that outcomes after lung and esophageal surgery appear to be related to factors other than surgical volumes alone. Harrison and colleagues ${ }^{5}$ acknowledge the inherent limitations of database research, and they have used multilevel mixedeffects regression models to account for clustering at the hospital level. Admittedly, the analysis does not evaluate volume as a continuous variable, and it does not consider the interplay of surgeon volume versus hospital volume, as it is possible for a low-volume hospital to host data from a high-volume surgeon, potentially confounding comparisons from hospital to hospital.

Is evaluating quality metrics after oncologic thoracic surgery perhaps more than a numbers game? Does practice 
make perfect in the world of thoracic surgery? The answer is not a clear yes, but neither is it a clear no. There are several factors other than volume that have tremendous impact on surgical outcomes and are often neglected in the policy-making sector. Beyond volume, our societies should evaluate the effects on patient outcomes of surgeon training, quality of surgery, access to multidisciplinary teams, and surgeon decision-making support. The most likely truth is that practice is but one part of being perfect. Minimum volume standards oversimplify the multidimensional nature of surgical outcomes research and should probably not be used as proxies of quality in isolation of other important parameters. Numbers don't lie, but they can be complex.

\section{References}

1. Luft HS, Bunker JP, Enthoven AC. Should operations be regionalized? The empirical relation between surgical volume and mortality. N Engl J Med. 1979;301:1364-9.

2. Birkmeyer JD, Dimick JB, Birkmeyer NJ. Measuring the quality of surgical care: structure, process, or outcomes? J Am Coll Surg. 2004;198:626-32.

3. Birkmeyer JD, Siewers AE, Finlayson EV, Stukel TA, Lucas FL, Batista I, et al. Hospital volume and surgical mortality in the United States. $N$ Engl J Med. 2002;346:1128-37.

4. Livingston EH, Cao J. Procedure volume as a predictor of surgical outcomes. JAMA. 2010;304:95-7.

5. Harrison S, Tangel V, Wu X, Christos P, Gaber-Baylis L, Turnbull Z, et al. Are minimum volume standards appropriate for lung and esophageal surgery? $J$ Thorac Cardiovasc Surg. 2018;155:2683-94.e1.

6. Kozower BD, Stukenborg GJ. Volume-outcome relationships in thoracic surgery. Thorac Surg Clin. 2017;27:251-6.

7. Bendzsak AM, Baxter NN, Darling GE, Austin PC, Urbach DR. Regionalization and outcomes of lung cancer surgery in Ontario, Canada. J Clin Oncol. 2017;35: 2772-80. 